\title{
Left circumflex coronary artery aneurysm with arteriovenous fistula to the coronary sinus presenting as acute coronary syndrome
}

\author{
Aleksander Siniarski ${ }^{1}$, Paweł Rostoff ${ }^{1}$, Bartosz Laskowicz ${ }^{2}$, \\ Radosław Rychlak', Jadwiga Nessler', Grzegorz Gajos ${ }^{1}$ \\ 1 Department of Coronary Disease and Heart Failure, Institute of Cardiology, Jagiellonian University Medical College, John Paul II Hospital, Kraków, Poland \\ 2 Department of Radiology and Diagnostic Imaging, John Paul II Hospital, Kraków, Poland
}

Correspondence to:

Aleksander Siniarski, MD, Oddział Kliniczny Choroby Wieńcowej i Niewydolności Serca z Pododziałem Intensywnego Nadzoru Kardiologicznego, Instytut Kardiologii, Uniwersytet Jagielloński, Collegium Medicum, Krakowski Szpital Specjalistyczny im. Jana Pawła II, ul. Prądnicka 80, 31-202 Kraków, Poland, phone: +48 1261422 18, e-mail: aleksandersiniarski@gmail.com Received: October 18, 2016 Revision accepted: October 21, 2016 Published online: November 28, 2016 Conflict of interests: none declared Pol Arch Med Wewn. 2016. 126 (11): 899-900 doi:10.20452/pamw.3658 Copyright by Medycyna Praktyczna Kraków 2016
A 61-year-old Caucasian woman with a history of ischemic heart disease, hypertension, type 2 diabetes, and hypercholesterolemia was admitted to the hospital due to unstable angina. Three months prior to hospitalization, an exercise treadmill test was performed showing a significant downsloping ST-segment depression of $1.5 \mathrm{~mm}$ in leads III, aVF, and $V_{4}-V_{6}$, at 7 metabolic equivalents of exercise with no chest pain. A physical examination was unremarkable, blood pressure was 130/75 mmHg, and the pulse rate was regular $(66 \mathrm{bpm})$. An electrocardiogram on admission revealed inferolateral ST-segment depression with ST-segment elevation in lead aVR, suggesting diffuse subendocardial ischemia. Routine blood test results were normal. The measurement of high-sensitivity cardiac troponin levels yielded negative results. Urgent transthoracic echocardiography showed no wall motion abnormalities with normal left ventricular ejection fraction of $65 \%$. On a computed tomography (CT) angiography, a fistula from the circumflex artery $(\mathrm{Cx})$ to coronary sinus was suspected (FIGURE 1A-C). The coronary angiography confirmed a large fistula between an aneurysmatic $\mathrm{Cx}$ and the coronary sinus without coronary artery stenosis (FIGURE 1D). After a heart team consultation, the patient was referred for a surgical fistula closure and then successfully operated on. One year after the surgery, a CT angiography excluded any communication between the $\mathrm{Cx}$ and coronary sinus. After a 6-year follow-up, the patient is in good general condition without any symptoms of angina.

Coronary arteriovenous fistulas are uncommon anomalies that are observed in 3 to 8 cases per thousand of coronary angiograms. ${ }^{1,2}$ Furthermore, aneurysmal formation of the artery drained by the fistula is uncommon. ${ }^{1}$ Usually, fistula arises from the right or left anterior descending coronary artery; therefore, $\mathrm{Cx}$ fistulas are unique. A great majority of fistulas bypass the blood from the arterial to venous systems, such as the pulmonary artery, coronary sinus, superior vena cava, or right-sided heart chambers. Most patients remain asymptomatic. ${ }^{1}$ Possible clinical presentations of coronary fistulas include angina, myocardial infarction, heart failure symptoms, endocarditis, arrhythmias, and they are related with the size and location of a fistula. ${ }^{3}$ Of note, most patients develop symptoms of myocardial ischemia in their fourth to sixth decade of life. ${ }^{4}$ Myocardial ischemia associated with coronary fistulas can be secondary or, less common, primary. ${ }^{4}$

Coronary steal syndrome was a possible explanation of angina in our patient. Potential complications of coronary fistulas are aneurysmal remodeling of drained artery, which was present in our patient, and rupture or thrombosis of the fistula. Coronary angiography is the gold standard for diagnosing coronary fistula. ${ }^{1}$ Nevertheless, noninvasive methods such as color-flow Doppler ultrasound, magnetic resonance imaging, and computed tomography can be useful in diagnosis, as they show the exact shape and anatomy of arteriovenous connections of fistulas. ${ }^{5}$ Treatment is recommended only for symptomatic patients, and possible options are surgical or transcatheter fistula closure. Surgical treatment was the most common technique until the introduction of transcatheter techniques in carefully selected patients with suitable anatomy of the fistula, namely, accessible with a closure device and with no other indications for surgery. ${ }^{1}$ Coronary artery fistulas, although rare, should be considered in a differential diagnosis of chest pain, particularly in young patients without known risk factors of atherosclerosis. 
FIGURE 1 A, B -

3-dimensional

reconstruction of

computed tomography:

a left circumflex coronary

artery $(\mathrm{Cx})$ aneurysm with

an arteriovenous fistula to the coronary sinus

(arrows); C, D - coronary angiography: a $\mathrm{Cx}$ aneurysm with an arteriovenous fistula to the coronary sinus (arrows)
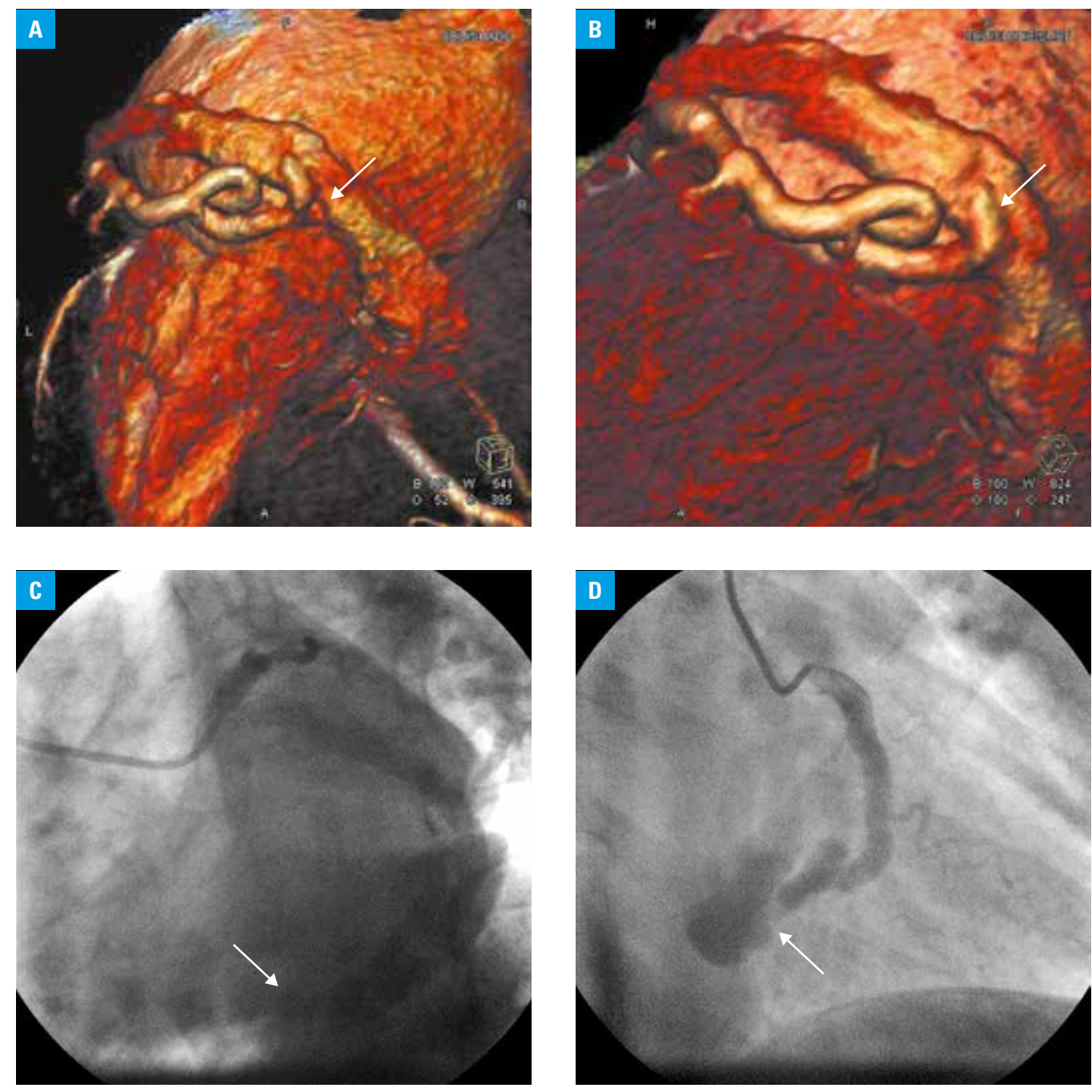

Acknowledgments The publication was supported by a grant from the National Science Centre Poland (2011/03/B/NZ5/0576; to GG) and by a grant from the Faculty of Medicine, Jagiellonian University Medical College (K/ZDS/005642; to GG).

\section{REFERENCES}

1 Gowda RM, Vasavada BC, Khan IA. Coronary artery fistulas: clinical and therapeutic considerations. Int J Cardiol. 2006; 107: 7-10.

2 Skrzypek A, Gackowski A, Szot W, et al. Anomalous origin and interarterial course of the right coronary artery: Diagnostic and therapeutic dilemmas. Pol Arch Med Wewn. 2014; 124: 746-747.

3 Balanescu S, Sangiorgi G, Castelvecchio S, et al. Coronary artery fistulas: clinical consequences and methods of closure. A literature review. Ital Hear J. 2001; 2: 669-676.

4 Angelini P. Coronary artery anomalies: an entity in search of an identity. Circulation. 2007; 115: 1296-1305.

5 Mittal UK. A case of coronary cameral fistula with associated aneurysm: role of ECG gated 256- slice dual source multidetector computed tomography in diagnosis. J Clin Diagnostic Res. 2016; 10 (LCx): 1-2. 